\title{
QUANTIFYING THE CONTRIBUTIONS OF CLIMATE CHANGE AND HUMAN ACTIVITIES TO THE DRAMATIC REDUCTION IN RUNOFF IN THE TAIHANG MOUNTAIN REGION, CHINA
}

\author{
WANG, S. ${ }^{1}-\mathrm{LI}, \mathrm{Q}^{2^{*}}-\mathrm{WANG}, \mathrm{J}^{1}$ \\ ${ }^{I}$ School of Geographical Science, Shanxi Normal University, Linfen 041004, Shanxi Province, \\ P. R. China \\ ${ }^{2}$ Institute of Geographical Sciences, Hebei Academy of Sciences, Hebei Engineering Research \\ Center for Geographic Information Application, Shijiazhuang 050011, Heibei Province, \\ P. R. China \\ *Corresponding author \\ e-mail:qingli2020@outlook.com \\ (Received 21 $1^{\text {st }}$ May 2020; accepted $17^{\text {th }}$ Sep 2020)
}

\begin{abstract}
The Taihang Mountain region, known as "the North China Water Tower", is an important water source guarantee for the Jing-Jin-Ji Urban Agglomeration. Recently, a dramatic reduction of runoff has seriously threatened to the regional ecological security. Quantitative attribution of such remarkable reduction in runoff is important for designing sustainable watershed management strategies in the changing environment. This study selected three typical basins in the north, middle and south regions, the Zhangfang, Weishui and Guantai basins, to quantitatively attribute the reduction in runoff to climate change and human activities by using the physics-based Soil and Water Assessment Tools (SWAT). The results suggested that the annual runoff of three basins all decreased by over $60 \%$ since the change-point year of 1983, 1975 and 1973. Based on the SWAT model, the contribution rates of human activities are $54.19 \%, 60.16 \%$ and $68.39 \%$ for Zhangfang, Weishui and Guantai basins, respectively. Additionally, the contribution rates of climate change are $45.81 \%, 39.84 \%$ and $31.61 \%$. The increased contribution rate of human activities from north to south indicates the gradually intensifying anthropogenic influence, which is reflected in water consumption.
\end{abstract}

Keywords: rainfall-runoff variation, climate change, ecological security, water environment, SWAT

\section{Introduction}

The water cycle controls the process of natural and human development. It not only links "geosphere - biosphere - atmosphere" together, but also is the key issue of the three global change research themes of "carbon cycle, food fiber and water cycle" (Chen and Xia, 1999; Vörösmarty et al., 2000; Bekele et al., 2010). Climate change is a basic factor on regional water resources. IPCC AR5 indicated global climate had been warming continuously since the middle of 20th century. Problems caused by climate change include redistribution of precipitation, increasing frequency of extreme weather events, etc. (IPCC, 2014; Qin et al., 2014). The response of water cycle to climate change is characterized by "nonlinearity, regionalism and uncertainty". Clarifying the unsteady driving and feedback mechanism of the hydrological regime has become a major challenge for hydrological science (Xia et al., 2007; Liu et al., 2014). On the other hand, intensive human activities, such as urbanization, industrial and agricultural water consumption, soil and water conservation measures and water conservancy projects, have resulted in dramatic changes of land surface conditions, which have threatened ecosystem stability (Milly et al., 2005; Zhao et al., 2014; Fu et al., 2017; Sun et al., 2020). Runoff variation, which has been impacted by climate change and human 
activities, reflects the characteristics of hydrological evolution (Yao et al., 2016; Zhao et al., 2018; Yang et al., 2019). At present, understanding the hydrological process, studying on the law of river runoff change and its driving mechanism under changing environment have become the hotspot of hydrological science.

The Taihang Mountain region, known as "the North China Water Tower", is a water guarantee and sand barrier for the Jing-Jin-Ji Urban Agglomeration. It provides $70 \%$ of the surface water resources to the North China Plain. In recent years, annual runoff of many rivers in this region, such as San-kan River, Hu-tuo River and Zhang River, showed significantly decreasing trend (Yang and Tian, 2009; Wang et al., 2013; Zhang et al., 2017). Water resource shortages and related environmental problems have seriously threatened local water resources security (Chu et al., 2010). Studies showed that climate change (temperature, precipitation, etc.) and human activities (groundwater exploitation, water conservancy project, and land use change, etc.) are the main driving factors (Chen and Xia, 1999; Liu and Xia, 2004). Based on the SWAT model, Zhang et al. (2017) presented the contribution rates of climate change and human activities for the runoff decrease in San-kan River Basin were 39.1\% and 60.9\%, respectively. Using three methods including hydrological model, hydrological sensitivity analysis and climate elasticity method, Wang et al. (2013) estimated that $70 \%$ of the runoff decrease was caused by climate change, while $30 \%$ was attributed to human activity in the $\mathrm{Hu}-$ tuo River Basin during 1957-2000. Meanwhile, the contribution rates of climate change and human activities in Zhang River Basin were 34\% and 66\%, respectively. A similar result was obtained by Bao et al. (2012) in Zhang River Basin by using the VIC hydrological model. The contribution rates of climate change and human activities were $26.1 \%$ and $73.9 \%$, respectively.

In the Taihang Mountain region, studies on attribution of runoff change were often carried out in a single river basin, which ignored the comparison of spatial differences. Therefore, Zhangfang, Weishui and Guantai basins, located in the north, middle and south of Taihang Mountain are selected as study areas. Using the SWAT model, we analyzed the spatial and temporal variation of regional runoff, quantitatively distinguished the contribution of climate change and human activity to runoff variation. It not only offers scientific support for the sustainable utilization of water resource, but also has important values for regional socio-economic development.

\section{Materials and methods}

\section{Study area}

The Taihang Mountain region $\left(35.15^{\prime} \mathrm{N} \sim 40.46{ }^{\prime} \mathrm{N}, 110.14^{\prime} \mathrm{E} \sim 116.333^{\prime} \mathrm{E}\right)$ is an important geographical boundary of eastern China, which lies to the east of the Loess Plateau and the west of the North China Plain. This region is the headwater of many rivers, including Daqing River, Ziya River, Nanyun River and Qinhe River, with an area of approximately $134,900 \mathrm{~km}^{2}$. Among them the Daqing, Ziya and Nanyun rivers flow east to Haihe River, and Qinhe River enters the Yellow River. There is obvious difference in climate and landscape between east and west of the Taihang Mountain region. The eastern side is the North China Plain. Its climate is warm and humid, and the dominant landscape is deciduous broad-leaved forest. The west side belongs to the Loess Plateau, where located in semi-humid and semi-arid transition zone, and the dominant landscape are forest, grassland and steppe. Zhangfang, Weishui and Guantai basins belong to Daqing River, Ziya River, and Nanyun River systems, which are located in the northern, 
central and southern parts of the Taihang Mountain region, respectively (Fig. 1, Table 1). Owing to the large span from north to south, analysis of typical basins in different regions can better reflect runoff variation rules of the Taihang Mountain region and the runoff response to human activities and climate change.

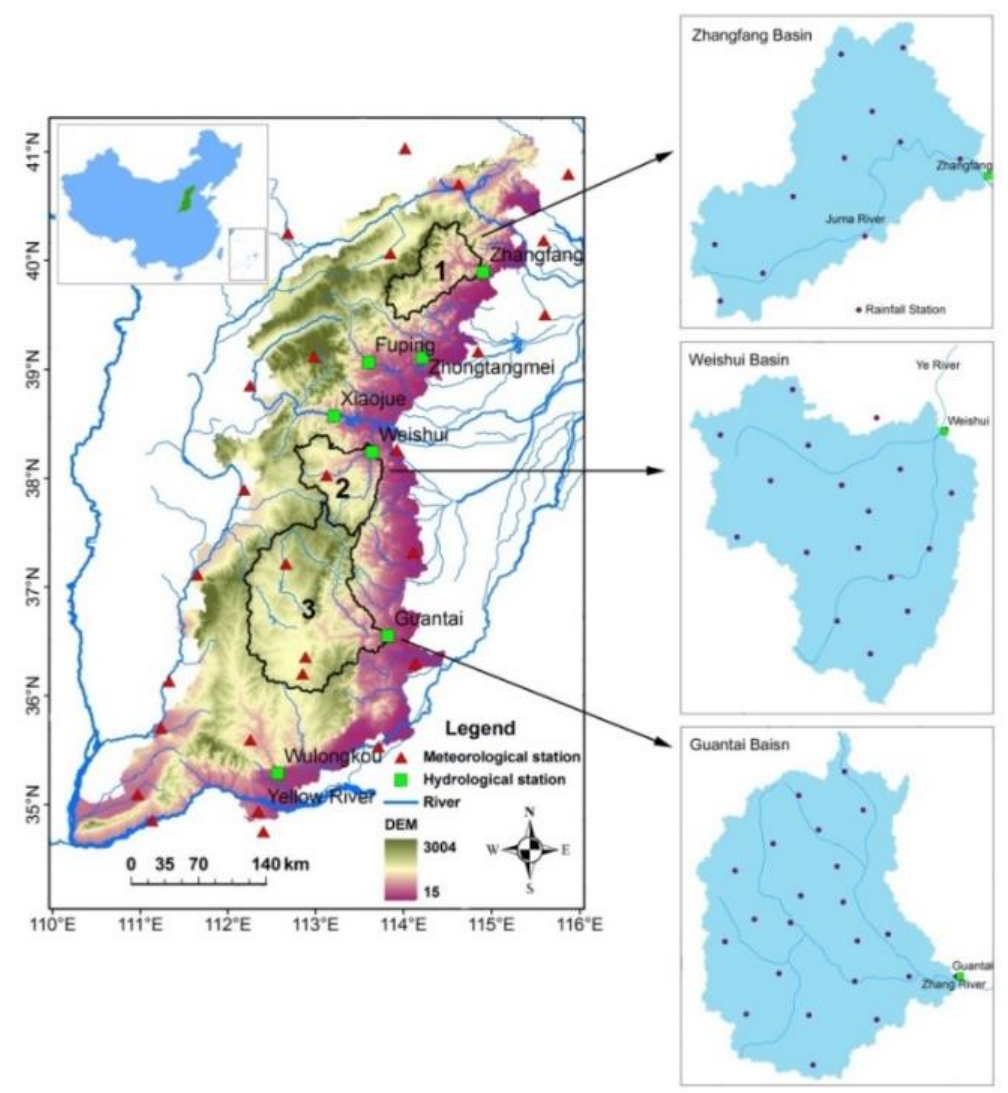

Figure 1. Location of the Taihang Mountain region and three selected basins

Table 1. The basic information of Zhangfang, Weishui and Guantai Basins

\begin{tabular}{c|c|c|c|c|c}
\hline Basin & $\begin{array}{c}\text { Area }^{*} \\
\left(\mathrm{~km}^{2}\right)\end{array}$ & $\begin{array}{c}\text { Precipitation } \\
(\mathrm{mm})\end{array}$ & $\begin{array}{c}\text { Cultivated land } \\
\text { coverage }^{*}(\%)\end{array}$ & $\begin{array}{c}\text { Vegetation } \\
\text { coverage }^{*}(\%)\end{array}$ & $\begin{array}{c}\text { Total reservoir } \\
\text { storage }^{* * *}\left(10^{8} \mathrm{~m}^{3}\right)\end{array}$ \\
\hline Zhangfang & 4833 & 467 & 11.93 & 86.51 & 3.03 \\
Weishui & 5485 & 481 & 25.19 & 70.26 & - \\
Guantai & 17668 & 529 & 40.41 & 55.94 & 7.12 \\
\hline
\end{tabular}

-: missing; *: obtained by land use data in 2015; **: average annual precipitation from 1955 to 2017;

$* * *$ : total reservoir storage in 2012

\section{Data sources}

The fundamental datasets used in this study include: meteorological, hydrological and remote sensing data. The meteorological data are derived from 20 meteorological stations and 51 rainfall stations around the Taihang Mountain region during 1951-2017, including air temperature, precipitation, wind speed and direction, relative humidity and sunshine duration. The hydrological data contain monthly runoff data from the Zhangfang, Weishui and Guantai hydrological stations during 1955-2017, which are 
from the China Hydrological Yearbook-Haihe River Basin. Remote sensing data are consisted of land use, soil and Digital Elevation Model (DEM). Land use raster data (spatial resolution: $100 \times 100 \mathrm{~m}$ ) in 2000, 2005, 2010 and 2015 are provided by the Data Center for Resources and Environment Sciences Chinese Academy of Sciences (http://www.resdc.cn/). The soil type and property data are completed by the Institute of Soil Science, Chinese Academy of Science. DEM is from the Shuttle Radar Topography Mission, with a resolution of $90 \mathrm{~m}$.

\section{Soil and Water Assessment Tool (SWAT)}

The Soil and Water Assessment Tool was used to quantitatively analyze the impact of climate change and human activities on hydrological processes. SWAT is a physically-based model developed by the U.S. Department of Agriculture (USDA) Agricultural Research Service (ARS). In the model, the Soil Conservation Service (SCS) curve number method was used for predicting surface runoff from daily rainfall (Neitsch et al., 2011; Arnold et al., 2012). Climate change and human activities are driving factors of runoff variation. According to the abrupt change year for the annual runoff, the research period is divided into natural and interferential phases. The natural phase is the period before abrupt change year, without significant variation in runoff, which shows that water recycling remains natural state without human activities. The interferential phase follows the abrupt change year and shows that hydrological process is significantly affected by both climate change and human activities.

Using the meteorological and hydrological data in natural phase, the parameters of SWAT model can be calibrated, and then a hydrological model suitable for the study area is built (Ficklin et al., 2009; Furey et al., 2012). The simulation in natural phase reflect the hydrological characteristics of a basin under natural conditions, while the simulation in interferential phase reflect the runoff change affected by both climate change and human activities. Thus, the difference between the simulated and observed runoff in the interferential phase presents the impact of human activities on runoff. The formula is as follows (Eqs. 1-4):

$$
\begin{gathered}
\Delta Q=Q_{o b v}=\Delta Q_{\text {climate }}+\Delta Q_{\text {human }} \\
\Delta Q_{\text {human }}=Q_{\text {sim }}-Q_{o b v} \\
\lambda_{\text {climate }}=\frac{\Delta Q_{\text {climate }}}{\Delta Q} \times 100 \% \\
\lambda_{\text {human }}=\frac{\Delta Q_{\text {human }}}{\Delta Q} \times 100 \%
\end{gathered}
$$

where $\Delta Q(\mathrm{~mm})$ is total runoff change; $\Delta Q_{\text {climate }}(\mathrm{mm})$ is runoff change caused by climate change; $\Delta Q_{\text {human }}(\mathrm{mm})$ is runoff change caused by human activities; $Q_{\text {sim }}$ and $Q_{o b v}(\mathrm{~mm})$ are simulated and observed runoff in the interferential phase, respectively; $\lambda_{\text {climate }}(\%)$ is contribution of climate change to runoff change; $\lambda_{\text {human }}(\%)$ is contribution of human activities to runoff change. 


\section{Results}

\section{Runoff change analysis}

Fig. 2 illustrates the interannual variations and abrupt change testing results in runoff for Zhangfang, Weishui and Guantai basins during 1955-2017. The annual runoff of three basins all showed decreasing trend, at the rates of $-0.116,-0.122$ and $-0.305 \times 10^{8}$ $\mathrm{m}^{3} \mathrm{a}^{-1}$, respectively. Mann-Kendall Method, a non-parametric statistical test method (Hirsch and Slack, 1984), was used to test the abrupt changes of annual runoff. The results showed the abrupt change was in 1983, 1975 and 1973 for Zhangfang, Weishui and Guantai basins, respectively. And the runoff continued to significantly decrease thereafter. Before and after abrupt change year, the annual average runoff in Zhangfang Basin decreased by $3.38 \times 10^{8} \mathrm{~m}^{3}(63.9 \%)$, from $5.29 \times 10^{8} \mathrm{~m}^{3}$ to only $1.91 \times 10^{8} \mathrm{~m}^{3}$. Meanwhile, the total loss in runoff for Weishui and Guantai basins were $5.04 \times 10^{8} \mathrm{~m}^{3}$ $(76.6 \%)$ and $13.19 \times 10^{8} \mathrm{~m}^{3}(74.9 \%)$, respectively.

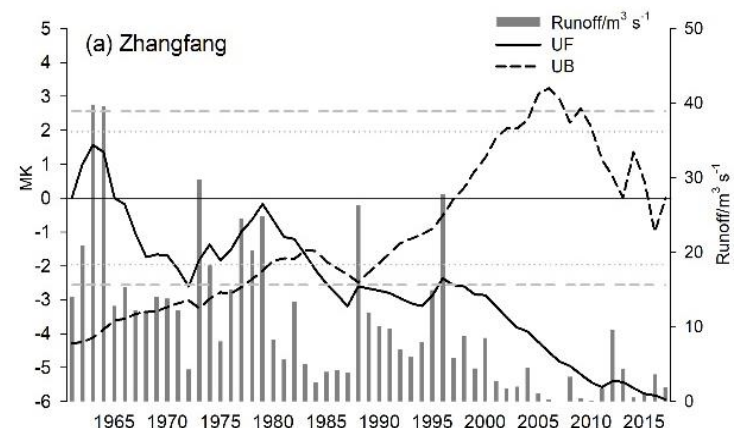

19651970197519801985199019952000200520102015

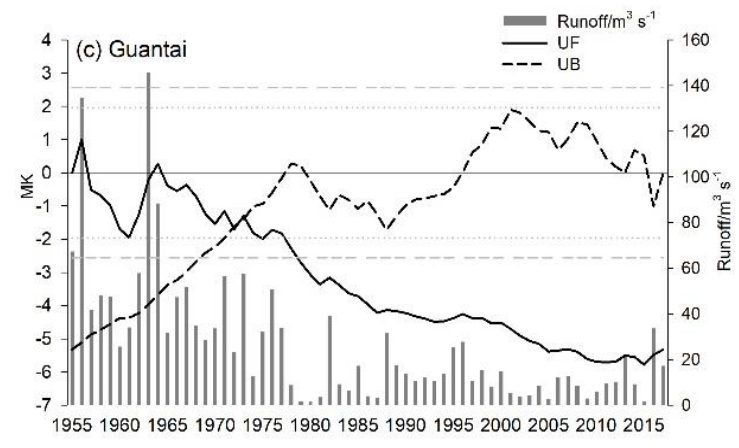

Figure 2. Interannual variations and Mann-Kendall's testing statistics values of runoff for Zhangfang, Weishui and Guantai basins during 1955-2017

The seasonal variations of runoff in three basins displayed similar characteristics before and after abrupt change year (Fig. 3). The monthly runoff appeared unimodal distribution, with flood and non-flood seasons. The average runoff of each month in the interferential phase was lower than that in the natural phase, and the maximum decrease occurred in August, with a reduced amount of $43.57 \mathrm{~m}^{3} / \mathrm{s}, 72.56 \mathrm{~m}^{3} / \mathrm{s}$ and $126.41 \mathrm{~m}^{3} / \mathrm{s}$, respectively. The relative reduction rate all passed 55\% in each month of Zhangfang Basin, with the maximum relative deduction rate in April. In Weishui Basin, the maximum relative deduction rate was in August, with $84.99 \%$, while the minimum relative deduction rate occurred in winter. The Guantai Basin had a stable relative reduction rate throughout the year, passing $70 \%$. 

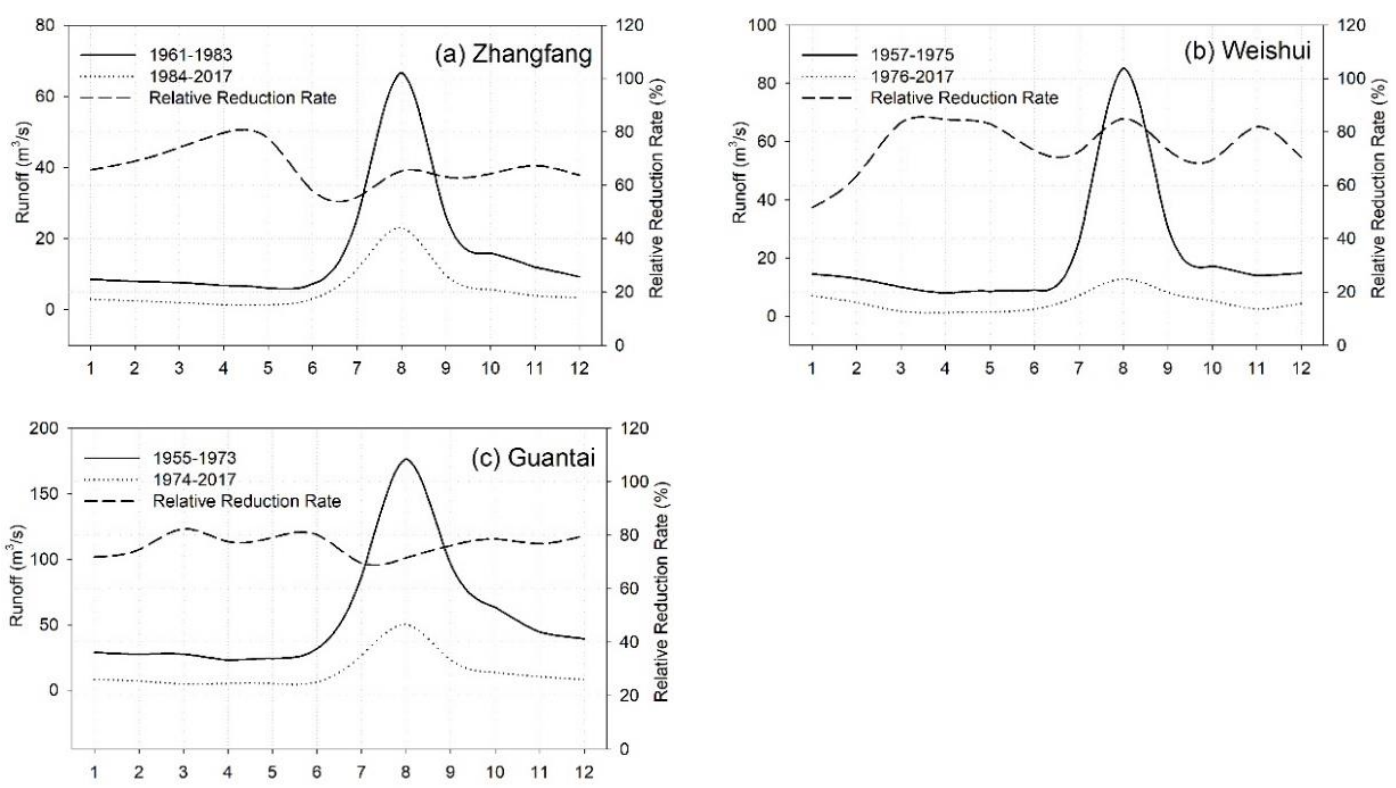

Figure 3. Monthly average runoff and relative reduction rate for three basins before and after abrupt change point

Runoff coefficient is a key index which reflects the capacity of water yield in a basin. In the natural and interferential phases, runoff coefficient decreased from 0.23 to 0.09 in Zhangfang Basin, from 0.24 to 0.05 in Weishui Basin, and from 0.18 to 0.05 in Guantai Basin. It indicated that the effect of recent climate change on runoff reduction was gradually weakened, and the impact of intense human activities gradually increased from north to south. The relationship between runoff and precipitation in the natural and interferential phases is shown in Fig. 4. Compared with the annual runoff depth in the natural phase, it decreased sharply in the interferential phases. The variation in annual runoff depth decreased from $36.1 \mathrm{~mm}$ to $18.0 \mathrm{~mm}$ for $100 \mathrm{~mm}$ decrease in precipitation for Zhangfang Basin in the two periods, with a reduction of $18.1 \mathrm{~mm}$. Meanwhile, the reduction of annual runoff depth was $15.2 \mathrm{~mm}$ and $24.2 \mathrm{~mm}$ in Weishui and Guantai Basin. In the interferential phase, the correlation between runoff and precipitation decreased significantly in Zhangfang and Guantai Basin. The annual runoff depth was less than $100 \mathrm{~mm}$ in most years (97.5\%) in three basins, especially in Weishui Basin, almost all less than $50 \mathrm{~mm}$ during 1976-2017.

\section{Runoff simulation based on the SWAT model}

\section{Model performance}

Simulated and observed monthly runoff of the three basins is presented in Fig. 5. For Zhangfang basin, except the simulated runoff showed difference in the months with rainstorms and other hydrological events, the simulations were good in the whole period. The simulated runoff of Weishui basin were not good after August in the years 1960-1962 and 1971-1975. For Guantai basin, the peak values from June to September in the years 1958-1961 were overestimated, while the values in August were underestimated in most other years. Nevertheless, the model performance needs to be evaluated by the relative error, $R^{2}$ (correlation coefficient) and $E_{N S}$ (Nash-Suttcliffe simulated coefficient). In the calibrated phase, the relative error between the simulated and observed monthly runoff in Zhangfang, 
Weishui and Guantai basins was $4.43 \%, 16.48 \%$ and $6.82 \%$, respectively. $\mathrm{R}^{2}$ was $0.94,0.96$ and $0.79, E_{N S}$ was $0.84,0.86$ and 0.90 , respectively. In the validated phase, the relative error between the simulated and observed monthly runoff of three basins was $12.48 \%, 17.68 \%$ and $11.50 \%$, respectively; $R^{2}$ was $0.73,0.77$ and 0.79 , and $E_{N S}$ was $0.65,0.80$ and 0.84 , respectively. The relative error in the two phases is less than $15 \%, R^{2}>0.6$ and $E_{N S}>0.5$, which means the simulated results meet the accuracy requirement, and the SWAT model can be well applied to the three basins.
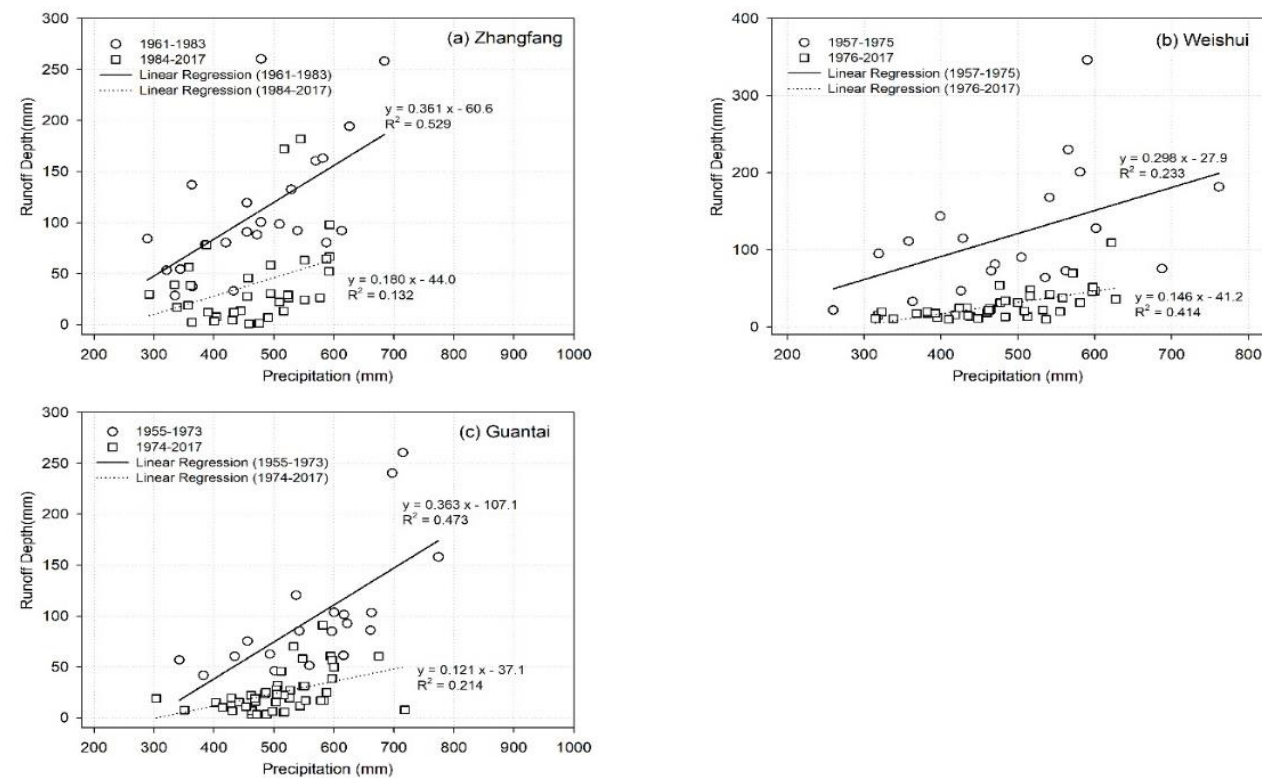

Figure 4. Relationship between annual precipitation and runoff during the two periods divided by abrupt change years
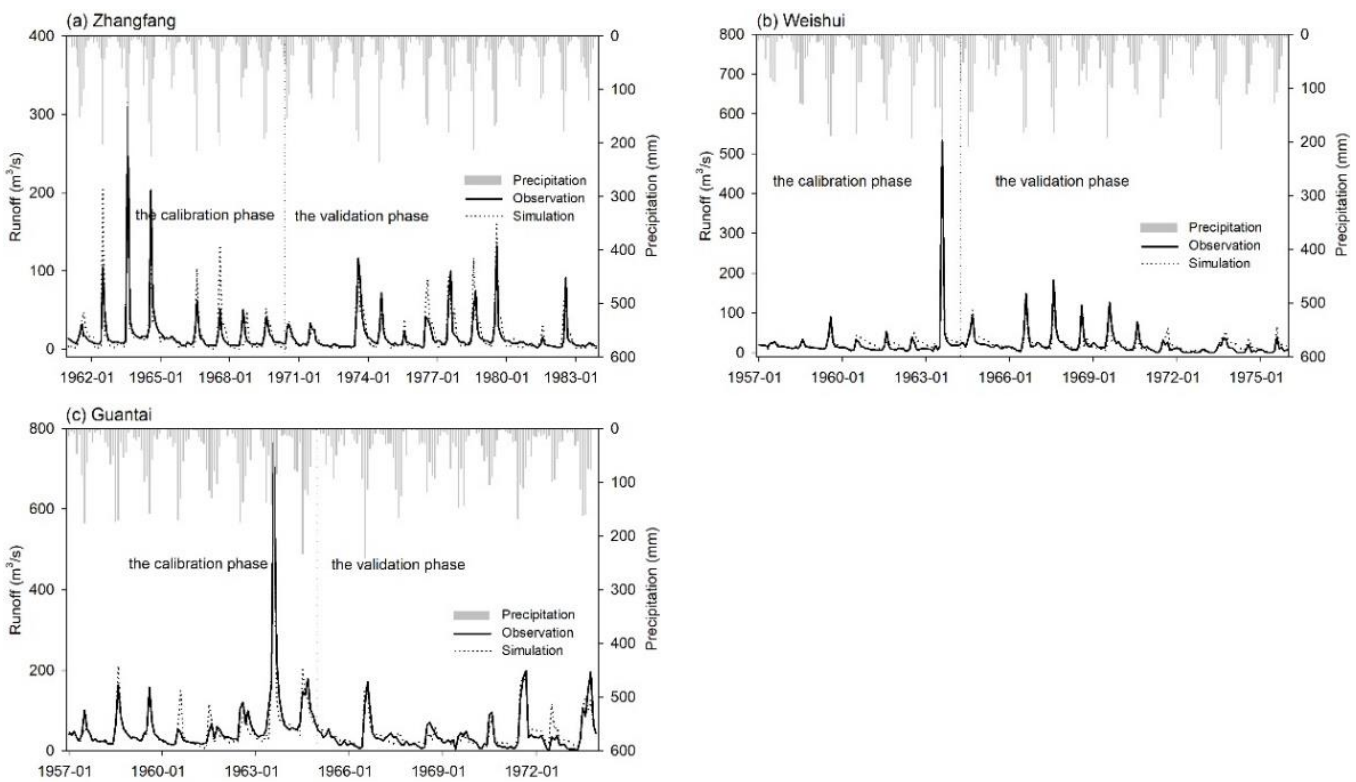

Figure 5. Comparison between observed and simulated monthly runoff for Zhangfang (19611983), Weishui (1957-1975) and Guantai (1957-1973) basin 
Fig. 6 compares the observed and simulated annual runoff of the three basins in different periods based on the calibrated SWAT model. In the natural period, $R^{2}$ for Zhangfang, Weishui and Guantai basins were 0.82, 0.97 and 0.86 , respectively, and $E_{N S}$ were $0.81,0.85$ and 0.82 , respectively. The significant differences between the simulated and observed annual runoff started from 1983, 1975 and 1973, respectively, which is consistent with the runoff abrupt change year. This result shows that SWAT model can be used to analyze the response of runoff to climate change and human activities.
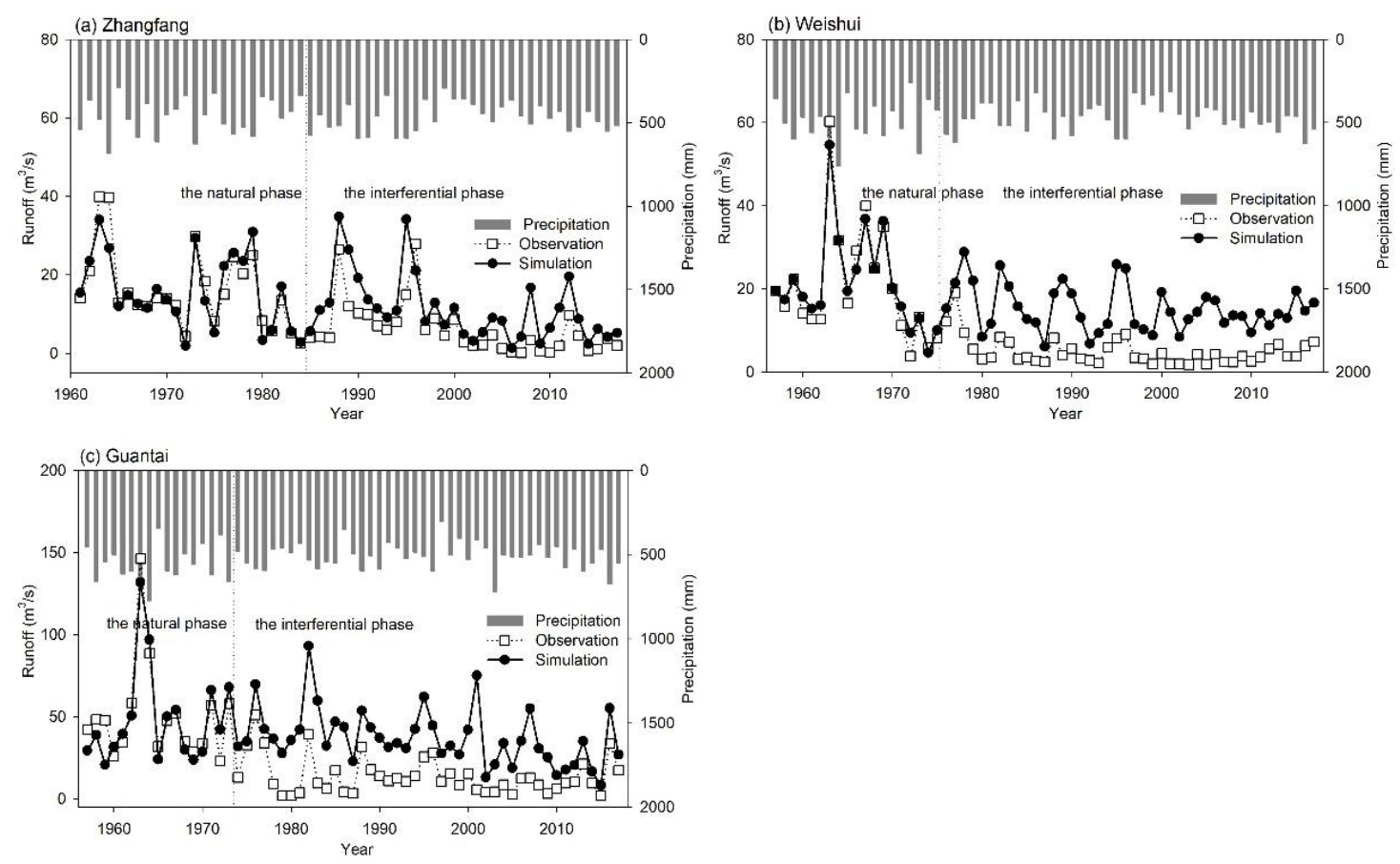

Figure 6. Simulated and observed annual runoff in the natural and the interferential phase for the three basins

\section{Contributions of climate change and human activities to runoff reduction}

As shown in Table 2, for Zhangfang Basin, annual runoff reduced from $109.43 \mathrm{~mm}$ in the natural period (1961-1983) to $39.55 \mathrm{~mm}$ in the interferential period (1984-2017), with a $69.88 \mathrm{~mm}$ reduction. Meanwhile, the natural runoff in the two periods built by the SWAT model was $106.66 \mathrm{~mm}$ and $74.65 \mathrm{~mm}$, with a $32.01 \mathrm{~mm}$ reduction. The average annual runoff observed in Weishui basin reduced to $28.08 \mathrm{~mm}$ in the interferential period (1976-2017) compared with $120.05 \mathrm{~mm}$ in the natural period (1957-1975), with $91.97 \mathrm{~mm}$ reduction. The natural runoff in the two periods built by the SWAT model was $123.76 \mathrm{~mm}$ and $87.13 \mathrm{~mm}$, with a $36.64 \mathrm{~mm}$ reduction. The average annual runoff observed in Guantai basin reduced to $24.98 \mathrm{~mm}$ in the interferential period (1974-2017) from $90.05 \mathrm{~mm}$ in the natural period (1957-1973), with a $65.07 \mathrm{~mm}$ reduction. The natural runoff of the two periods built by the SWAT model was $86.67 \mathrm{~mm}$ and $66.10 \mathrm{~mm}$, with a $20.57 \mathrm{~mm}$ reduction. Thus, the contribution rates of climate change to runoff reduction in Zhangfang, Weishui and Guantai basins, as calculated by formula in Eqs. 1-4, were $45.81 \%, 39.84 \%$ and $31.61 \%$, respectively, while the contribution rates of human activities were $54.19 \%, 60.16 \%$ and $68.39 \%$. 
Table 2. Contributions of climate change and human activity for decreasing runoff based on SWAT model

\begin{tabular}{c|c|c|c|c|c|c|c}
\hline \multirow{2}{*}{ Basin } & Period & Observed & Simulated & \multirow{2}{*}{$\begin{array}{c}\text { Observed } \\
\text { runoff } / \mathrm{mm}\end{array}$} & $\begin{array}{c}\text { Simulated } \\
\text { runoff } / \mathrm{mm} \\
\text { runoff } \\
\text { change } / \mathrm{mm}\end{array}$ & \multicolumn{2}{|c}{ SWAT model } \\
\cline { 7 - 8 } & & & & $\begin{array}{c}\text { Contribution } \\
\text { of Climate } \\
\text { Change } / \%\end{array}$ & $\begin{array}{c}\text { Contribution } \\
\text { of Human } \\
\text { Activity } / \%\end{array}$ \\
\hline Zhangfang & $1961-1983$ & 109.43 & 106.65 & 69.88 & 32.01 & 45.81 & 54.19 \\
& $1984-2017$ & 39.55 & 74.65 & & & & \\
Weishui & $1957-1975$ & 120.05 & 123.76 & 91.97 & 36.64 & 39.84 & 60.16 \\
& $1976-2017$ & 28.08 & 87.13 & & & & \\
Guantai & $1957-1973$ & 90.05 & 86.67 & 65.07 & 20.57 & 31.61 & 68.39 \\
\hline
\end{tabular}

The contribution of climate change and human activities to monthly runoff reduction can be calculated using the same method (Fig. 7) and the similar results were obtained. In Zhangfang basin, the highest contribution of climate change to runoff occurred in August, with a rate of $72.66 \%$, and its contribution in other months fluctuated around $40 \%$. In Weishui and Guantai basins, the highest contribution of climate change was $59.00 \%$ and $42.25 \%$, respectively, likewise in August. The seasonal distribution patterns of contribution rates are similar in the two basins: the maximum climate change contribution occurred in summer, less in winter, and lowest in spring and autumn.
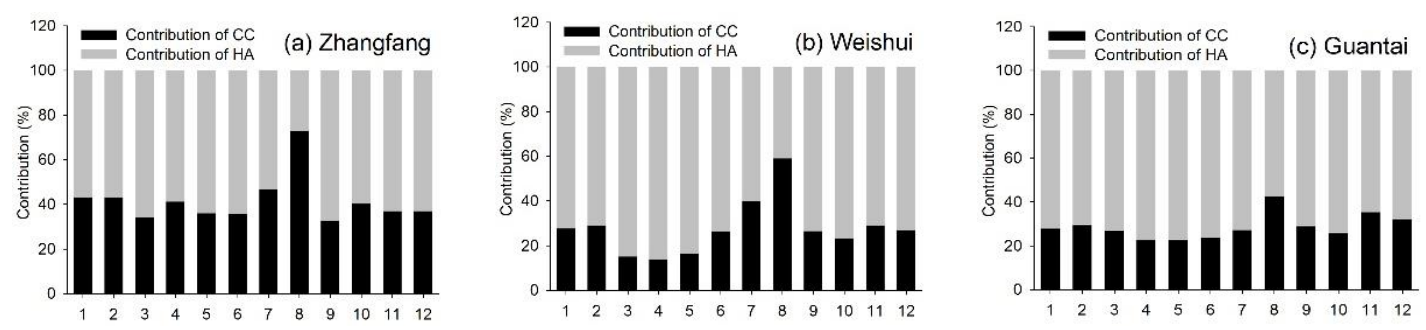

Figure 7. Contributions of climate change and human activity for decreasing monthly runoff in the three basins based on SWAT model (CC: Climate Change, HA: Human Activity)

\section{Discussion}

Based on the SWAT method, the contribution rate of climate change on runoff in the three basins is lower than that of human activities, which implies human activities are the main impact factor for runoff decrease in the Taihang Mountain region. At the same time, the contribution rate of human activities in the three basins increases from north to south, which indicates that the influence of human activities from north to south is increasing.

The effect of human activities in the basin is reflected in water consumption, the variation in human water consumption directly reduced the water availability in rivers, and its effect was different in three basins. As shown in Fig. 8, both annual and per capita water consumption in the Zhangfang basin showed similar decreasing trends during 1991-2018, and the human water consumption reduced sharply after 2012. In addition, the surface water only supplied $23.5 \%$ of the human water consumption, with a utilization rate of $9.8 \%$, thus the groundwater was a more important water source. 

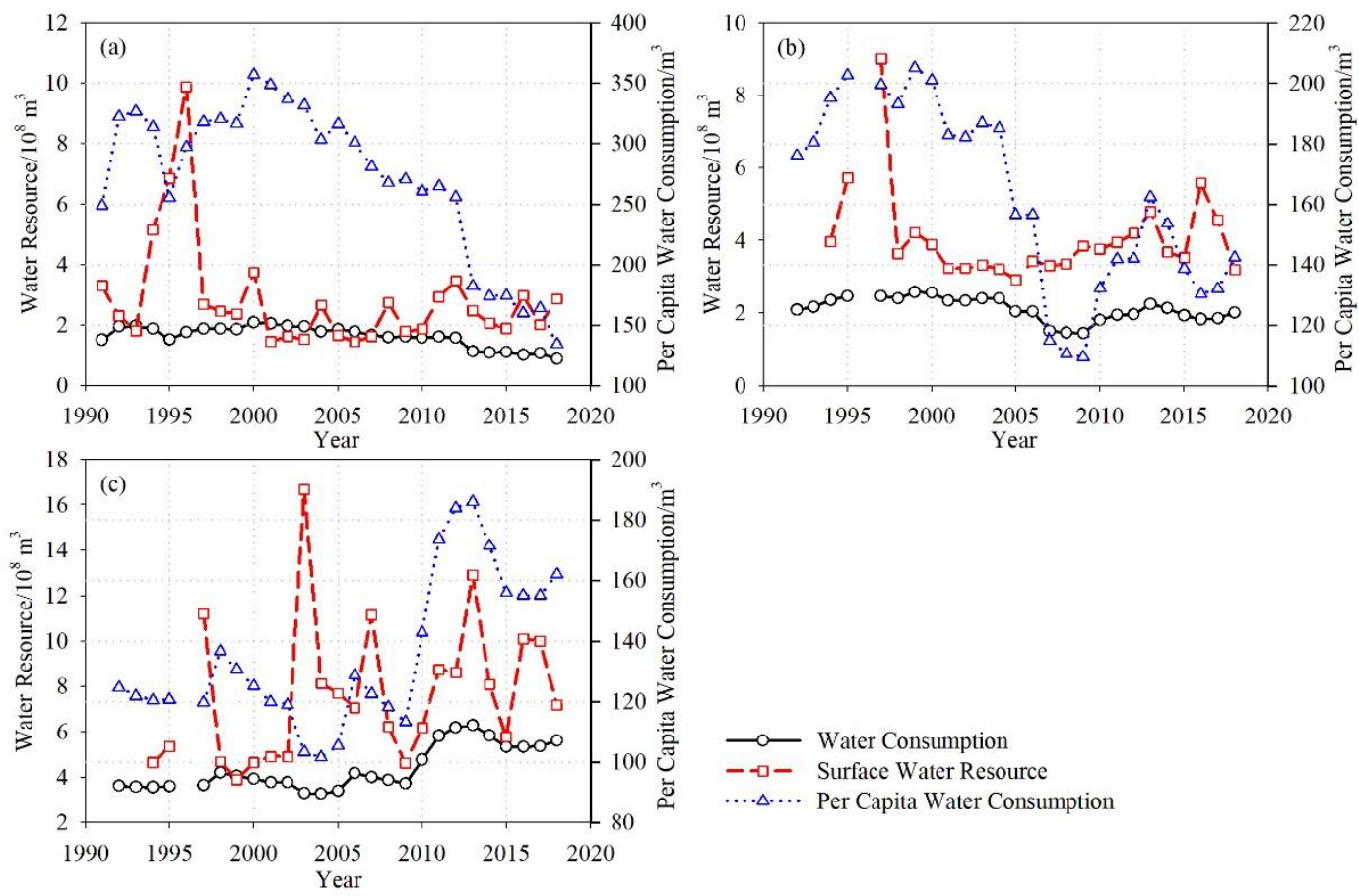

$-\infty$ Water Consumption

$-\square-$ Surface Water Resource

$\cdots \Delta \cdots$ Per Capita Water Consumption

Figure 8. Per capita water consumption, total human water consumption, and surface water resource in the (a) Zhangfang, (b) Weishui and (c) Guantai basin

The series of annual and per capita water consumption in the Weishui basin presented the same abrupt point at 2004 by using the Mann-Kendall Method (Hirsch and Slack, 1984). Before and after abrupt year, both above series decreased firstly and then increased. The annual average water consumption reduced from $2.38 \times 10^{8} \mathrm{~m}^{3} / \mathrm{a}$ to $1.91 \times 10^{8} \mathrm{~m}^{3} / \mathrm{a}$ in two periods, and the per capita water consumption reduced by $51.22 \mathrm{~m}^{3} / \mathrm{a}$. The surface water supplied $64.9 \%$ of the human water consumption, with a utilization rate of $30.6 \%$. In the basin, the farmland accounted for about $25 \%$ and was mainly dry farmland. The Jingxing and Xiyang County were known as the agricultural regions in the upstream. The effective irrigation area increased to $3109 \mathrm{hm}^{2}$ in 2000 compared with $1190 \mathrm{hm}^{2}$ in 1990. In addition, Yangquan City in the basin is an important energy and heavy industry base. The industrial, mining and residential land in 2000 increased by $8.3 \%$ compared with the 1980s. Human water consumption reached to the peak. Hereafter, the water consumption continued to fall until 2009 due to the effect of landscape engineering measures, while the increasing ecological and environmental water consumption led to the recent increase of total water usage (20102018).

Guantai basin is an area with intense human activities, farmland covers about $53.4 \%$, and construction land covers $7.5 \%$. There are three large reservoirs in the basin, with total reservoir storage $7.12 \times 10^{8} \mathrm{~m}^{3}$ and covering about $29.81 \%$ of the basin. The annual water consumption showed a significant increasing trend during 1992-2018, with a rate of $962.56 \times 10^{4} \mathrm{~m}^{3} / \mathrm{a}$. The series had an abrupt point at 2009 , and the average water consumption increased from $3.74 \times 10^{8} \mathrm{~m}^{3} / \mathrm{a}$ to $5.43 \times 10^{8} \mathrm{~m}^{3} / \mathrm{a}$. Meanwhile, the average per capita water consumption increased from $119.96 \mathrm{~m}^{3} / \mathrm{a}$ to $160.00 \mathrm{~m}^{3} / \mathrm{a}$ before and after abrupt point. The surface water supplied $46.1 \%$ of the human water consumption, with a utilization rate of $27.9 \%$. 


\section{Conclusions}

Based on the analysis of trend and abrupt change for climate and hydrological factors in the Taihang Mountain region during 1955-2017, a SWAT hydrological model was built to simulate the hydrological process of the Zhangfang, Weishui and Guantai basins, and then the model was used to quantitatively estimate the contribution of climate change and human activity on runoff decrease. According to the above study, several facts were worth highlighting:

- The annual runoff of the Taihang Mountain region showed a decreasing trend during 1955-2017, and the abrupt change occurred at 1983, 1975 and 1973 for Zhangfang, Weishui and Guantai basins, respectively. The monthly runoff decreased by over $60 \%$ before and after abrupt change point.

- According to the comparison between observed and simulated runoff, the relative errors in the natural phase are less than $15 \%, R^{2}>0.6$ and $E_{N S}>0.5$. The simulated results meet the accuracy requirement; thus the calibrated SWAT model can be well applied to the three basins.

- Through SWAT model, the contribution rates of human activity (climate change) in Zhangfang, Weishui and Guantai basins are $45.81 \%$ (54.19\%), 39.84\% $(60.16 \%)$ and $31.61 \%$ (68.39\%), respectively. Compared to climate change, human activity is a more important factor for runoff reduction in the Taihang Mountain region.

In the current study, we assume that the impacts of climate change and human activities on the water cycle at a river basin are independent, while the two factors have an interaction effect. Further, human activities include many factors, such as land use/cover change, water engineering measures, human water consumption, and government policies. In the future, an improved hydrological model, considering a variety of anthropogenic influence factors in detail, is needed to establish for simulating the water cycle process in the basins. Based on this model, a research on the future prediction of runoff changes will also be carried out. By setting different scenarios, the hydrologic regulation effects of the Grain-for-Green program, check-dams and terraces on runoff will be explored. The results can provide scientific basis and decision support for rational allocation of water resources and comprehensive management of ecological environment in the Taihang Mountain region.

Acknowledgments. This research was funded by the National Natural Science Foundation of China (No. 41801034), the Open Research Fund of Key Laboratory of Tibetan Environmental Changes and Land Surface Processes, Chinese Academy of Sciences (TEL201801), the National Basic Research Program of China (973 Program, No. 2015CB452705).

\section{REFERENCES}

[1] Arnold, J. G., Moriasi, D. N., Gassman, P. W., Abbaspour, K. C., White, M. J., Srinivasan, R., Santhi, C., Harmel, R. D., Griensven, A. V., Liew, M. W. V., Kannan, N., Jha, M. (2012): SWAT: Model use, calibration, and validation. - Transactions of the ASABE 55(4): 1345-1352.

[2] Bao, Z., Zhang, J., Wang, G., Fu, G., He, R., Yan, X. (2012): Attribution for decreasing streamflow of the Haihe River Basin, Northern China: climate variability or human activities? - Journal of Hydrology 460-461: 117-129. 
[3] Bekele, E. G., Knapp, H. V. (2010): Watershed modeling to assessing impacts of potential climate change on water supply availability. - Water Resources Management 24(13): 3299-3320.

[4] Chen, J. Q., Xia, J. (1999): Facing the challenge: barriers to sustainable water resources development in China. - Hydrological Sciences Journal 44(4): 507-516.

[5] Chu, J. T., Xia, J., Xu, C. Y., Li, L., Wang, Z. G. (2010): Spatial and temporal variability of daily precipitation in Haihe River Basin, 1958-2007. - Journal of Geographical Sciences 20(2): 248-260.

[6] Ficklin, D. L., Luo, Y. Z., Luedeling, E., Zhang, M. H. (2009): Climate change sensitivity assessment of a highly agricultural watershed using SWAT. - Journal of Hydrology 374(1-2): 16-29.

[7] Fu, B. J., Wang, S., Liu, Y., Liu, J. B., Liang, W., Miao, C. Y. (2017): Hydrogeomorphic ecosystem responses to natural and anthropogenic changes in the Loess Plateau of China. - Annual Review of Earth \& Planetary Sciences 45(1): 223-243.

[8] Furey, P. R., Kampf, S. K., Lanini, J. S., Dozier, A. Q. (2012): A stochastic conceptual modeling approach for examining the effects of climate change on runoffs in mountain basins. - Journal of Hydrometeorology 13(3): 837-855.

[9] Hirsch, R. M., Slack, J. R. (1984): A nonparametric trend test for seasonal data with serial dependence. - Water Resources Research 20(6): 727-732.

[10] IPCC. (2014): Climate Change 2014: Synthesis Report. - In: Core Writing Team, Pachauri R. K., Meyer, L. A. (eds.) Contribution of Working Groups I, II and III to the Fifth Assessment Report of the Intergovernmental Panel on Climate Change. IPCC, Geneva, Switzerland.

[11] Liu, C. M., Xia, J. (2004): Water problems and hydrological research in the Yellow River and the Huai and Hai River basins of China. - Hydrological Processes 18(12): 2197-2210.

[12] Liu, C. Z., Zhan, C. S., Xia, J., Cao, J. T. (2014): Review on the influences of climate change and human activities on runoff. - Journal of Hydraulic Engineering 45(4): 379385 .

[13] Milly, P. C. D., Dunne, K. A., Vecchia, A. V. (2005): Global pattern of trends in streamflow and water availability in a changing climate. - Nature 438: 347-350.

[14] Neitsch, S. L., Arnold, J. G., Kiniry, J. R., Williams, J. R. (2011): Soil and Water Assessment Tool: Theoretical documentation, version 2009. - In: Texas Water Resources Institute Technical Report no. 406. Texas A\&M University System, College Station, Texas.

[15] Qin, D. H., Stocker, T., 259 Authors and TSU (Bern \& Beijing) (2014): Highlights of the IPCC working group I fifth assessment report. - Progressus Inquisitiones de Mutatione Climatis 10(1): 1-6.

[16] Sun, P. C., Wu, Y. P., Gao, J. E., Yao, Y. Y., Zhao, F. B., Lei, X. H., Qiu, L. J. (2020): Shifts of sediment transport regime caused by ecological restoration in the Middle Yellow River Basin. - Science of the Total Environment 698: 134261.

[17] Vörösmarty, C. J., Green, P., Salisbury, J., Lammers, R. B. (2000): Global water resources: vulnerability from climate change and population growth. - Science 289(5477): 284-288.

[18] Wang, W. G., Shao, Q. X., Yang, T., Peng, S. Z., Xing, W. Q., Sun., F. C., Luo, Y. F. (2013): Quantitative assessment of the impact of climate variability and human activities on runoff changes: a case study in four catchments of the Haihe River basin, China. Hydrological Processes 27(8): 1158-1174.

[19] Xia, J., Zhang, L., Liu, C. M., Yu, J. J. (2007): Towards better water security in North China. - Water Resources Management 21(1): 233-247.

[20] Yang, Y. H., Tian, F. (2009): Abrupt change of runoff and its major driving factors in Haihe River Catchment, China. - Journal of Hydrology 374(3): 373-383. 
[21] Yang, X. N., Sun, W. Y., Li, P. F., Mu, X. M., Gao, P., Zhao, G. J. (2019): Integrating agricultural land, water yield and soil conservation trade-offs into spatial land use planning. - Ecological Indicators 104: 219-228.

[22] Yao, W. Y., Xiao, P. Q., Shen, Z. Z., Wang, J. H., Jiao, P. (2016): Analysis of the contribution of multiple factors to the recent decrease in discharge and sediment yield in the Yellow River Basin, China. - Journal of Geographical Sciences 26(9): 1289-1304.

[23] Zhang, L., Karthikeyan, R., Bai, Z. K., Srinivasan, R. (2017): Analysis of streamflow responses to climate variability and land use change in the Loess Plateau region of China. - Catena 154: 1-11.

[24] Zhao, G. J., Tian, P., Mu, X. M., Jiao, J. Y., Wang, F., Gao, P. (2014): Quantifying the impact of climate variability and human activities on runoff in the middle reaches of the Yellow River basin, China. - Journal of Hydrology 519: 387-398.

[25] Zhao, G. J., Mu, X. M., Jiao, J. Y., Gao, P., Sun, W. Y., Li, E., Wei, Y. H., Huang, J. C. (2018): Assessing response of sediment load variation to climate change and human activities with six different approaches. - Science of the Total Environment 639: 773-784. 